\title{
Mapeamento da incidência de dengue em Manaus (2008): estudo da associação entre fatores socioambientais na perspectiva da Geografia da Saúde
}

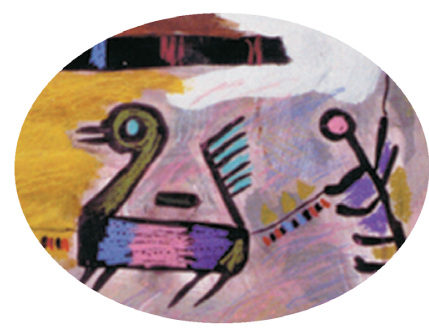

Renato Ferreira de Soura*

\section{Resumo}

A Geografia da Saúde tem caráter multidisciplinar quando se refere aos estudos sobre a dengue em Manaus. A associação entre urbanização, temperatura e pluviosidade como alguns fatores socioambientais propícios para a transmissão da dengue contribui dessa forma, como instrumento de estudo para a produção do espaço promotor da saúde, por parte do geógrafo.

Palavras-chave: Cidade de Manaus; mosquito Aedes aegypti; urbanização.

\begin{abstract}
The Geography of the Health has character multidisciplinar when it refers to the studies on the dengue in Manaus. The association between urbanization, temperature and pluviosidade as some factors socioambientais propitious for the transmission of the dengue contributes thus like study instrument for promoter's production space of the health by the geographer.
\end{abstract}

Keywords: City of Manaus; mosquito Aedes aegypti; urbanization.

\footnotetext{
* Mestre em Geografia pela Universidade Federal do Amazonas (UFAM), atualmente é geógrafo da Fundação de Vigilância em Saúde do Amazonas (FVS-AM). Lidera um grupo multidisciplinar de estudos em Geografia da Saúde cujo objetivo é proporcionar um espaço de debates voltados para a discussão do processo saúde-doença no Amazonas.
} 


\section{Introdução}

O entendimento da associação entre os fatores socioambientais e a incidência de dengue poderá auxiliar na identificação de potenciais condições para proliferação dessa doença. O objetivo central deste trabalho consiste em relacionar o comportamento da incidência de dengue em 2008, tendo como base a infestação predial de seus vetores, assim como associar com as variações de temperatura e de pluviosidade desse ano. Dessa maneira, a análise deste trabalho é compreender a distribuição da dengue na perspectiva da Geografia da Saúde e compreender as relações com os fatores socioambientais na cidade de Manaus.

O trabalho foi dividido em três partes, de modo a atender a análise dessa associação. A primeira parte procura abordar a metodologia utilizada para levantar os dados de infestação predial por meio dos Liraa(s). A segunda parte procura associar a urbanização, a temperatura e a pluviosidade como alguns fatores favorecedores da incidência da dengue. E, por fim, a terceira parte do trabalho procura analisar os dados do Liraa 2008, mapeando a distribuição da dengue nas zonas geográficas de Manaus.

Em função da sua estreita associação com o homem, o Aedes aegypti é, essencialmente, um mosquito urbano, encontrado em maior abundância em cidades, vilas e povoados. As fêmeas do mosquito se alimentam mais frequentemente de sangue, servindo como fonte de repasto e que, posteriormente, fornecerá proteínas para o desenvolvimento de seus ovos. Os ovos do Aedes aegypti são depositados pela fêmea, individualmente, nas paredes dos depósitos que servem como criadouros, próximo à superfície da água.

Uma vez completado o desenvolvimento embrionário, os ovos são capazes de resistir a longos períodos de dessecação, que podem prolongar-se por mais de um ano. Essa capacidade de resistência dos ovos à dessecação é um sério obstáculo para sua erradicação, pois os ovos podem ser transportados a grandes distâncias, em recipientes secos, tornando-se um meio de dispersão do inseto.

O Aedes aegypti vive relativamente pouco tempo, de trinta a trinta e cinco dias, porém muitas pessoas não tomam os cuidados necessários para combater a proliferação dele. Dessa forma, as atribuições do agente de endemias 
para o controle da dengue são: realizar a pesquisa larvária nos imóveis, realizar a eliminação de criadouros e orientar a população com relação aos meios de evitar a proliferação dos vetores.

É no ambiente urbano que o mosquito encontra o local propício para depositar seus ovos. Esse local é denominado de criadouro e trata-se de qualquer recipiente que armazene ou possa a vir a armazenar água. Por causa da expansão urbana de Manaus, é também atribuição do agente de endemias manter atualizado o cadastro de imóveis e os locais de grande concentração de depósitos preferenciais para a desova do mosquito Aedes aegypti.

\section{A metodologia do Levantamento de Índice Rápido do Aedes aegypti (Liraa)}

Com base nas informações da Fundação de Vigilância em Saúde do Amazonas (FVS-AM), a dengue no Estado do Amazonas teve caracterizada a introdução em 1998, com reprodução viral na capital, onde em 1996 foi detectada a presença de seu transmissor, o Aedes aegypti. Em 1998, a epidemia transcorreu por conta do sorotipo 1, chegando à notificação de 13.894 casos. Nos anos subsequentes, um número expressivo de casos também foi notificado pelos serviços de saúde.

Ao final do ano de 2000, foram detectados casos suspeitos, cujos isolamentos virais identificaram o vírus 2, desencadeando no ano seguinte nova epidemia de grandes proporções, com registro de 19.927 casos, sendo identificada a circulação dos vírus 1 e 2 . Nesse mesmo ano, detectou-se a presença de formas graves da doença, com 52 casos confirmados de dengue hemorrágica e a ocorrência de um óbito.

Em 2002 e 2003 o número de casos ainda foi expressivo, com 2.063 e 3.554 casos respectivamente, também se registrando no período a introdução do sorotipo 3. A partir de 2004, o número de casos notificados no Amazonas, e em particular em Manaus, manteve-se baixo, com registro de menos de mil casos anuais.

A partir do ano de 2005, o monitoramento da dengue em Manaus é realizado por meio da metodologia de Levantamento de Índice Rápido do Aedes aegypti (Liraa) e de forma sistemática a cada dois meses, a partir de 2006. Desde esse período, os resultados do Liraa têm servido como base para a intensificação das ações de controle vetorial, cujos setores onde são 
detectados os maiores índices são alvos de intensificação das ações integradas, compreendendo as equipes de controle vetorial e educação em saúde da Fundação de Vigilância em Saúde do Amazonas (FVS-AM) e secretaria de limpeza urbana de Manaus.

Essa metodologia torna-se importante para definição de ações e estratégias de ação, como condição essencial para a manutenção da doença sob controle, tendo em vista que a possibilidade de desenvolvimento de situações epidêmicas é um fato, principalmente determinada pelo sorotipo 3, até então suprimidas pelo desenvolvimento das ações de controle.

Ademais, a população da capital atualmente tem como principal corredor para o turismo a BR-174 (Manaus-Boa Vista), rodovia que dá acesso à Venezuela, onde circula o sorotipo 4. Nesse contexto, Manaus constitui-se uma cidade altamente vulnerável à entrada do sorotipo 4, pela grande mobilidade populacional verificada principalmente em período de férias escolares e em final de ano:

O Brasil está inserido no contexto epidemiológico americano do dengue, possui grandes extensões de fronteiras onde o controle e a vigilância de doentes e vetores são precários, além do intenso intercâmbio com países vizinhos. As condições epidemiológicas são propícias e os vários sorotipos têm grande potencial de disseminação, notadamente em regiões com alta concentração populacional, onde o caráter explosivo dos surtos traz grandes preocupações (DONALÍSIO, 1999: 93-94).

Com base nisso, o Levantamento de Índice Rápido do Aedes aegypti (Liraa) estabelece estratos de risco de acordo com o índice de infestação. Dessa forma, os locais com índice de infestação de até 1\% são considerados de baixo risco. Os locais com índice de infestação superior a 1 até $2 \%$ são considerados de médio risco, enquanto aqueles com índice superior a $2 \%$ são considerados de alto risco.

Essa metodologia contribui para gerar mapas que constituem a base geográfica da FVS-AM, servindo como referência para o desencadeamento de intensificação das ações de controle de forma integrada, em áreas prioritárias, 
compreendendo a intensificação da busca ativa de focos de larvas e tratamento, em áreas definidas como de alto risco. O software de mapeamento utilizado neste trabalho foi o MapInfo versão 8.5.

Além disso, a utilização do Liraa como indicador de condição de risco compreende numa tarefa de mobilização e de sensibilização junto à população, por meio de atividades de educação em saúde, em escolas, associações e outras instituições governamentais e não governamentais.

Conforme Brasil (2005: 23), (...) a disponibilização de mapas on croquis atualizados nos municípios é essencial para o planejamento operacional do Liraa. Essa base geográfica deverá disponibilizar informações sobre o número de quarteirões e os imóveis de cada bairro.

O procedimento de campo para o levantamento de índice inicia com a inspeção do primeiro imóvel do quarteirão, deslocando-se no sentido horário, contando-se quatro imóveis após o imóvel em inspeção para, em seguida, inspecionar o sexto imóvel (2. da amostra), e assim sucessivamente, inspecionando-se um imóvel em cada cinco, o que corresponde a inspecionar 20\% dos imóveis existentes no quarteirão sorteado. Em caso de o imóvel a ser inspecionado esteja fechado ou sua inspeção seja recusada, o agente de endemias deverá fazer sua substituição pelo imóvel imediatamente posterior.

\section{Os fatores socioambientais e a incidência de dengue}

Certas doenças estão associadas às condições climáticas. Conforme Ayoade (2002: 291), o clima também desempenha algum papel na incidência de certas doenças que atacam o homem (...). O mosquito Aedes aegypti tem grande capacidade de adaptação ao ambiente urbano e ao clima tropical, portanto é importante a atuação no sentido de controlar e combater o vetor.

A cidade de Manaus, por sua localização geográfica, é uma área urbana propícia para a proliferação do mosquito da dengue, pois é caracterizada por um clima quente e úmido, com índices pluviométricos elevados durante quase todos os meses do ano.

Como podemos observar na Figura 1, conforme dados obtidos pelo Instituto Nacional de Meteorologia (Inmet), Manaus apresenta duas estações distintas. A primeira, que compreende o período de julho a outubro, onde as temperaturas máximas médias ficam em torno de $33,5^{\circ} \mathrm{C}$, ocorrendo a 
diminuição das chuvas, onde a precipitação acumulada foi de $347 \mathrm{~mm}$. A segunda compreende o período de novembro a junho, onde as temperaturas máximas médias ficam em $31,3^{\circ} \mathrm{C}$, ocorrendo o aumento das chuvas, onde a precipitação acumulada foi de $2.507 \mathrm{~mm}$.

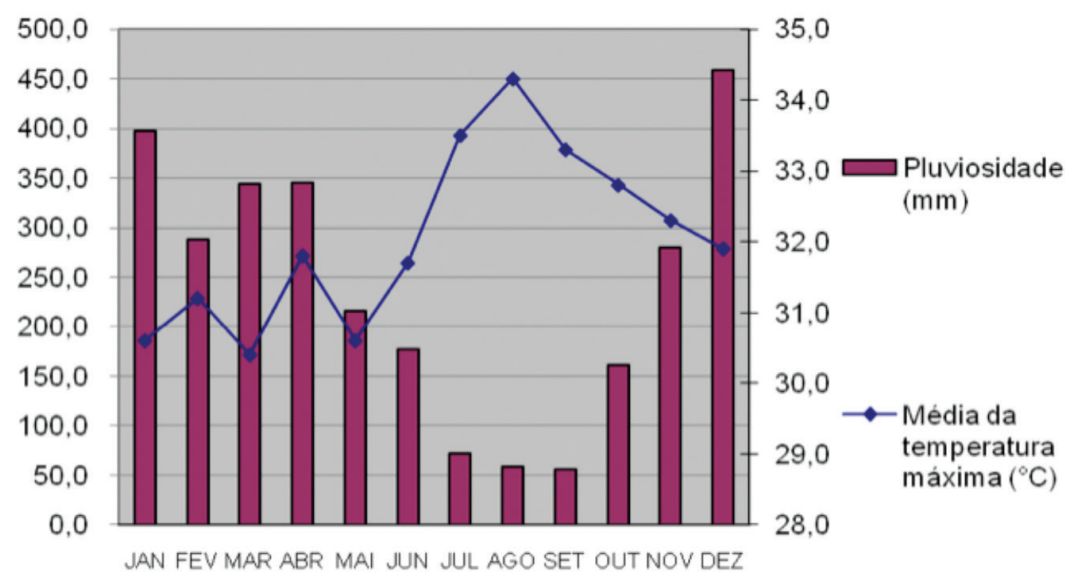

Figura 1 - Gráfico da pluviosidade e média da temperatura máxima em Manaus - 2008. Fonte - Inmet (2009). Org. e elab.: SOUZA (2010).

As intensas chuvas que ocorrem em Manaus, associada à temperatura e ao desmatamento urbano, são fatores que contribuem para a incidência de dengue. A perda da cobertura vegetal decorrente das ocupações desordenadas da população, em busca de terras para construir moradias, acaba criando ambientes propícios para a proliferação do mosquito.

Dessa forma, a questão ambiental deve ser entendida de uma maneira onde a sociedade possa estar atrelada à natureza. Para Mendonça (2005: 71), isso é de importância fundamental para a compreensão de como o meio ambiente vem sendo tratado pelas populações, conforme seus estágios de desenvolvimento socioeconômico-político.

O crescimento desordenado da cidade, principalmente com a criação da Zona Franca de Manaus em 1967, não deixou espaço para as árvores. A destruição de áreas verdes em Manaus está associada ao surgimento de novos bairros, muitos originados pelas "invasões" de terras, lideradas, muitas das vezes, por pessoas de baixo poder aquisitivo que vieram do interior ou de outros Estados.

Conforme o "Estudo do desmatamento na zona urbana de Manaus e 
sua relação com a expansão demográfica", realizado pelo Sipam, podemos analisar a perda da cobertura vegetal no período de 1986 a 2004. Esse estudo utilizou imagens TM/Landsat 5 da cena 231-062 dos anos de 1986, 1995 e 2004. Dessa forma, a Zona Franca de Manaus não trouxe nenhum benefício para a melhoria da qualidade de vida da maioria da população que ocupou essas áreas de expansão, resultando no agravamento dos problemas urbanos. Esse contexto é evidenciado quando há o aumento populacional, que se estende para as áreas verdes, ocorrendo, assim, o desmatamento urbano.

A retirada da vegetação serve para originar os novos bairros, todos com deficiência de saneamento básico, principalmente, com relação à coleta de lixo regular e ao abastecimento de água, sendo esses fatores socioambientais responsáveis pelo surgimento de criadouros do mosquito transmissor da dengue, pois garrafas, lixo e depósitos para armazenamento de água são criadores em potencial para a proliferação do vetor.

A cidade de Manaus possuía 24.866 ha de área verde no ano de 1986. Essa área foi reduzida para 15.265 ha no ano de 2004. Nesse período de dezoito anos houve uma perda de $38,6 \%$ da área verde da capital, configurando-se para uma evolução da expansão urbana em direção ao norte e a leste.

Nesse mesmo período, a zona norte teve uma redução de $72,9 \%$ de sua área verde e a zona leste teve uma redução de 41,4\%. Associado a essa perda da cobertura vegetal, essas duas zonas geográficas foram as que tiveram um crescimento populacional recente, contribuindo para o surgimento de novos bairros em Manaus.

Segundo o IBGE, conforme o Censo Demográfico de 2000, a zona leste possui 340.453 habitantes e a zona norte possui 282.083 habitantes, destacando-se como as zonas geográficas mais populosas de Manaus. A "pressão" demográfica se reflete nos dois bairros mais populosos da capital: Cidade Nova, com 193.490 habitantes (zona norte) e São José Operário, com 84.490 habitantes (zona leste).

As primeiras habitações construídas nesses novos bairros, muitas de forma rupestre, contrastam com o que havia no lugar. Muitas árvores foram derrubadas, principalmente em áreas de mananciais e nascentes de cursos d’água. Hoje, muitas dessas moradias estão localizadas em áreas de risco do Aedes aegypti, pois com a retirada da cobertura vegetal, elas foram construídas em locais com carência de infraestrutura urbana, como, por exemplo, a falta de 
rede de água encanada nesses lugares. A população acaba armazenando água para uso doméstico em tambores ou barris, que, sem o cuidado necessário, tornam-se criadouros do mosquito transmissor da dengue.

\section{A distribuição espacial da dengue por meio do Liraa}

A cidade de Manaus, capital do Estado do Amazonas, localiza-se aos $3^{\circ}$ de latitude sul e $60^{\circ}$ de longitude oeste. Apresenta uma população de 1.405 .835 habitantes (IBGE, 2000) distribuída numa área urbana que se estende por $377 \mathrm{~km}^{2}$. Pelo Decreto Municipal n. . 2.924/95, Manaus possui 56 bairros distribuídos em seis zonas geográficas: norte, leste, oeste, centro-oeste, centrosul e sul.

O Levantamento de Índice Rápido do Aedes aegypti (Liraa) foi realizado pela Fundação de Vigilância em Saúde do Amazonas (FVS-AM) em quatro períodos na cidade de Manaus em 2008. Com base nesses quatro levantamentos é possível explicar, por meio do índice de infestação predial, a associação que existe entre a pluviosidade, a temperatura e a crescente urbanização da cidade, como fatores socioambientais propícios para a incidência de dengue.

Para facilitar a aplicação da metodologia do Liraa, a cidade de Manaus foi mapeada em 55 estratos operacionais, sendo que os estratos são mapeados conforme uma área que compreende entre 8.000 a 12.000 imóveis.

O primeiro Liraa foi realizado no período de 7 a 11 de janeiro de 2008, onde Manaus apresentou precipitação acumulada de $97 \mathrm{~mm}$. Esse período corresponde à estação chuvosa, onde a temperatura média máxima ficou em $32^{\circ} \mathrm{C}$. Com base no índice de infestação predial, quase todas as zonas geográficas de Manaus apresentaram alto risco de incidência da doença, como podemos observar na Figura 2.

Os maiores índices foram encontrados no estrato 25 do bairro da Cidade Nova (zona norte) com 9,4\%, no estrato 45 dos bairros de Educandos e da Colônia Oliveira Machado (zona sul), com 13,5\% e no estrato 12 do bairro do Jorge Teixeira (zona leste) com 14,4\%. Ainda com relação a esse Liraa, os depósitos predominantes que foram encontrados na maioria dos bairros, tanto na zona norte como na zona leste, foram os de armazenamento de água para consumo humano. 


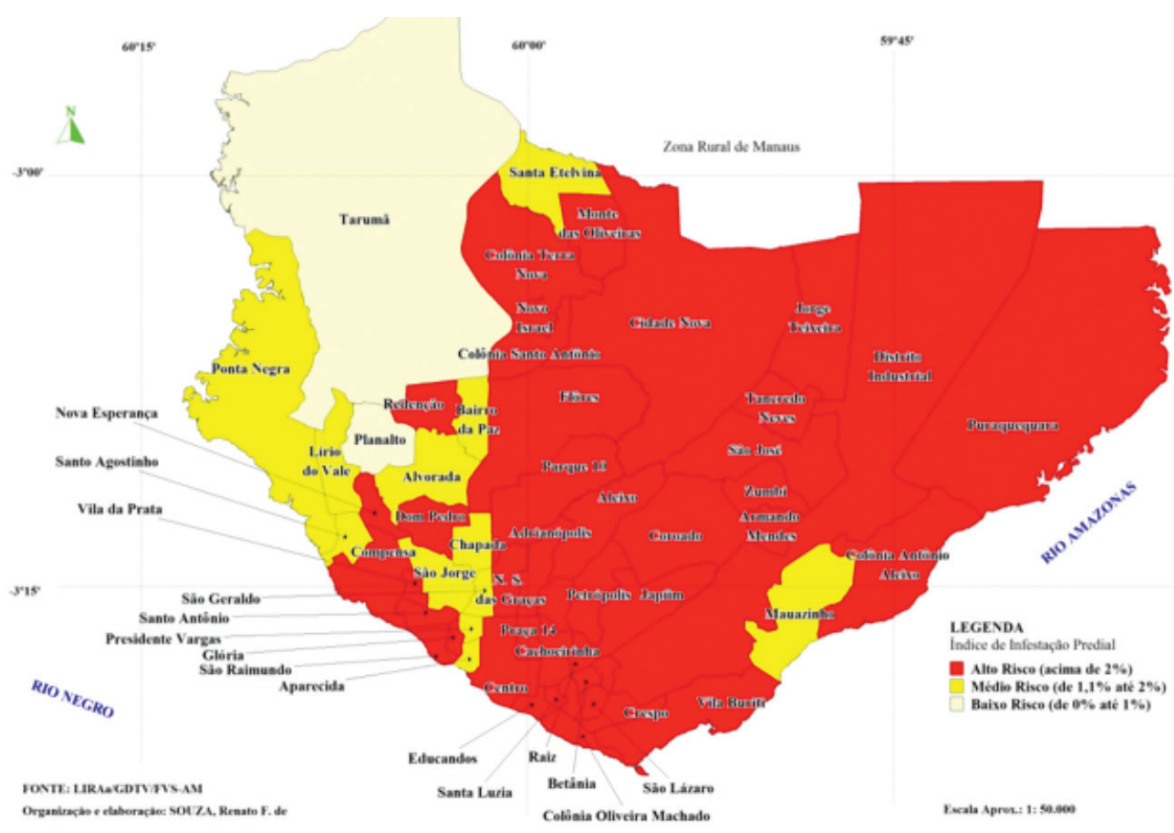

Figura 2 - Mapa do 1. ${ }^{\circ}$ Liraa de Manaus em 2008.

Fonte - SOUZA (2010).

Isso se deve ao fato de a maioria desses bairros terem sua origem em "invasões" de terra e, apesar de terem uma crescente urbanização, possuem sérios problemas relacionados à infraestrutura, como, por exemplo, a falta de água encanada.

A maioria da população da zona norte e da zona leste utiliza tambores e barris para armazenamento doméstico, onde muitas pessoas aproveitam a água da chuva para solucionar o problema da falta de água. O grande problema é o descaso da maioria da população que não toma os cuidados necessários para combater a proliferação do mosquito Aedes aegypti, tornando a zona norte e leste de Manaus como áreas de alto risco de dengue.

Nas zonas centro-sul e sul de Manaus, os depósitos predominantes encontrados na maioria dos bairros são aqueles relacionados ao lixo. São zonas geográficas da cidade que apresentam melhorias na infraestrutura, contribuindo para o desenvolvimento da atividade comercial. Aqui, o problema é o grande volume de lixo produzido, onde boa parte é descartada de forma inadequada, como recipientes plásticos, garrafas, latas ou sucatas, que acabam 
sendo jogados em terrenos baldios, tornando-se áreas de alto risco da dengue.

Quase todos os bairros que apresentaram baixo ou médio risco da doença estão localizados nas zonas oeste e centro-oeste. O estrato 27 do bairro do Tarumã (zona oeste) apresentou um índice de $0,6 \%$ e o estrato 30 do bairro do Planalto (zona centro-oeste) apresentou um índice de $0,8 \%$. O problema dessas zonas geográficas é o grande volume de lixo, resultante das atividades comerciais dessas áreas. Nesse tipo de ambiente propício à proliferação do mosquito Aedes aegypti, o estrato 38 do bairro da Compensa (zona oeste) e o estrato 35 do bairro do Dom Pedro (zona centro-oeste) apresentaram alto risco da doença, respectivamente com 5 e 4,3\%.

O segundo Liraa foi realizado no período de 5 a 14 de maio de 2008, onde a precipitação acumulada foi de $147 \mathrm{~mm}$, época ainda considerada de estação chuvosa na cidade de Manaus. A temperatura média máxima ficou em $30,4^{\circ} \mathrm{C}$. Com base no índice de infestação predial, as zonas geográficas de Manaus que mais preocupam são as zonas norte e leste, que apresentaram alto risco da doença, conforme a Figura 3.

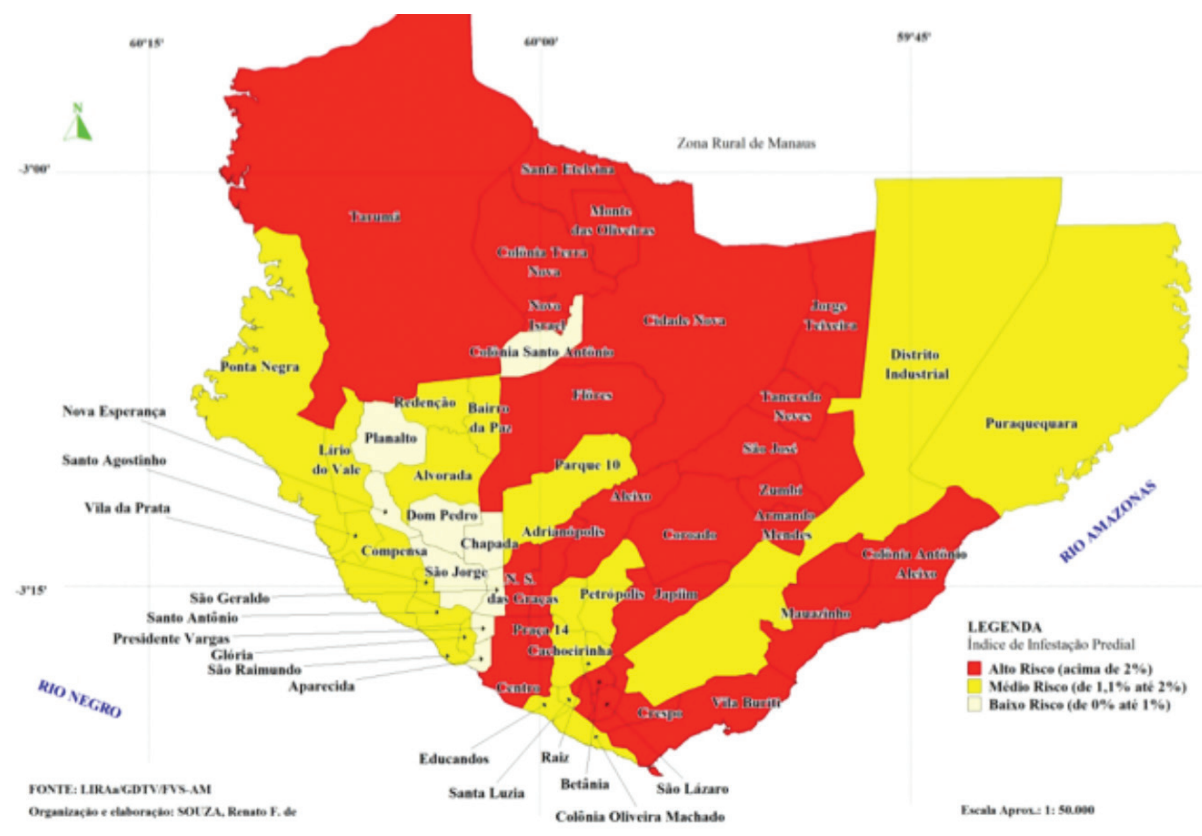

Figura 3 - Mapa do 2. ${ }^{\circ}$ Liraa de Manaus em 2008.

Fonte - SOUZA (2010). 
Os maiores índices foram encontrados no estrato 22 do bairro do Novo Israel (zona norte) com 8,6\% e no estrato 13 do bairro de Jorge Teixeira (zona leste) com 6,6\% Os menores índices foram encontrados no estrato 35 do bairro do Dom Pedro (zona centro-oeste) com $0,2 \%$ e no estrato 36 do bairro do São Jorge (zona oeste) com 0,6\%. Nesse Liraa é possível destacar, além do problema de depósitos de armazenamento de água nas zonas norte e leste, o aumento de depósitos predominantes referentes ao lixo em quase todos os bairros de Manaus.

Com base nisso, percebemos a necessidade de um trabalho intensivo de educação em saúde junto à população e eficiência no setor de limpeza pública. Outro problema até hoje não resolvido é a questão da falta de fornecimento de água encanada para muitos bairros das zonas norte e leste.

Segundo dados do IBGE, em 2000 existiam na cidade de Manaus 225.037 ligações de água, das quais apenas 81.256 eram medidas por hidrômetro, abastecendo 285.308 economias, sendo 269.329 de uso residencial, onde as redes de distribuição somavam $1.631 \mathrm{~km}$ de extensão. 15\% da população urbana é abastecida por poços particulares (GEO MANAUS, 2002: 60).

Com o crescimento populacional de Manaus, a urbanização cresceu no sentido norte e leste, onde a cobertura vegetal perdeu lugar para as moradias sem infraestrutura adequada, fazendo com que o mosquito transmissor da dengue encontre ambiente propício para reprodução, depositando seus ovos em recipientes de armazenamento d’água, típicos desses lugares.

O terceiro Liraa foi realizado no período de 4 a 15 de agosto de 2008, época em que Manaus apresentou precipitação acumulada de 7,6 mm, confirmando a estação de poucas chuvas na cidade. Nessa mesma época, Manaus apresenta médias térmicas elevadas, ficando em $34,7^{\circ} \mathrm{C}$, onde o ar quente carregado de umidade dá a sensação de calor insuportável. Novamente, com base no índice de infestação predial, as zonas norte e leste são as que apresentaram alto risco da doença, conforme observamos na Figura 4. 


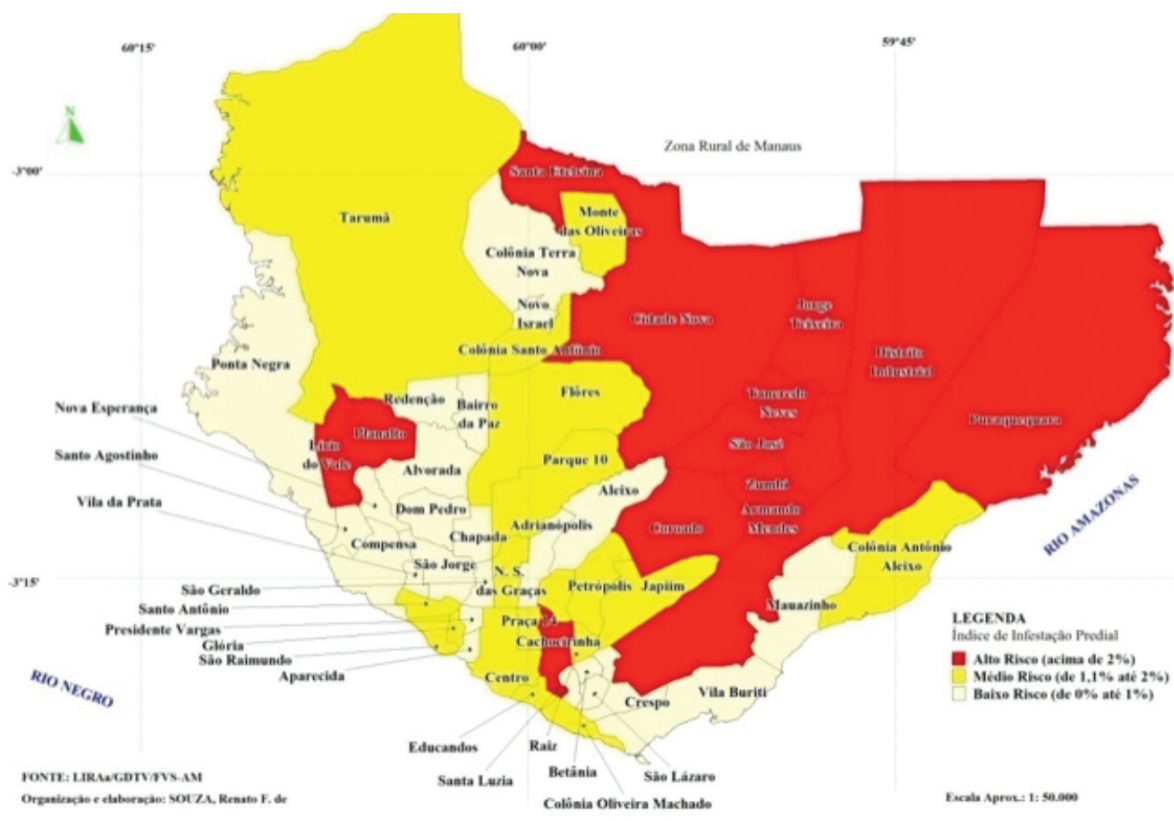

Figura 4 - Mapa do 3. . Liraa de Manaus em 2008. Fonte - SOUZA (2010).

Os maiores índices foram encontrados no estrato 13 do bairro do Jorge Teixeira (zona leste) com 7\% e no estrato 16 do bairro da Cidade Nova (zona norte) com 6,5\%. Esse Liraa demonstra, novamente, que o grande problema da zona norte e da zona leste é o depósito predominante referente ao armazenamento de água.

Com as elevadas temperaturas dessa época, a maioria da população armazena água para superar o problema da falta d'água encanada, servindo para o consumo e banho para amenizar o calor intenso. O lixo ainda continua sendo, também, um grande problema de depósitos predominantes em Manaus. Nesse Liraa podemos destacar, ainda, o maior número de bairros com baixo risco da doença, principalmente nas zonas oeste e centro-oeste.

O último Liraa de 2008 foi realizado no período de 13 a 23 de outubro, época em que Manaus apresentou precipitação acumulada de $11 \mathrm{~mm}$ e médias térmicas elevadas em $32,7^{\circ} \mathrm{C}$. Esses fenômenos ambientais, associados aos problemas urbanos como falta d'água encanada e destinação imprópria do 
lixo, são fatores que contribuem para a alta incidência de dengue:

\begin{abstract}
Sem dúvida, a "sazonalidade", a temperatura, o comportamento dos vetores, entre outras variáveis bioecológicas das epidemias de dengue, desempenham importante papel na viabilidade de transmissão. Algumas conclusões costumam orientar as medidas de controle da doença, pois esclarecem parte das chances concretas das diversas possibilidades epidêmicas. Porém perdem seu poder explicativo se forem examinadas como fatores independentes da realidade social em que ocorrem (DONALÍSIO, 1999: 60-61).
\end{abstract}

Nesse contexto, tendo como base o índice de infestação predial, esse Liraa demonstrou que a maioria dos bairros de Manaus apresentou alto risco da doença, conforme observamos na Figura 5.

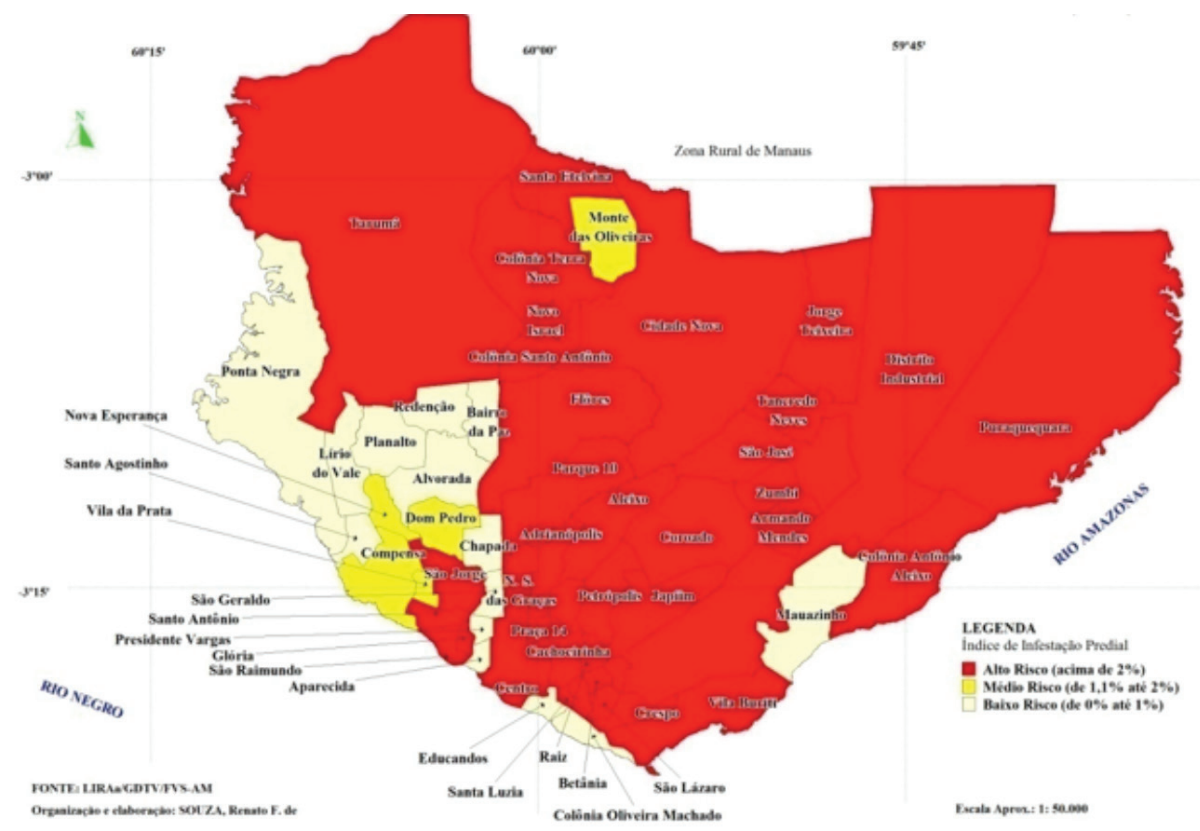

Figura 5 - Mapa do 4. ${ }^{\circ}$ Liraa de Manaus em 2008.

Fonte - SOUZA (2010). 
Os depósitos predominantes na maioria desses bairros foram aqueles relacionados ao armazenamento de água e também ao lixo. Vale ressaltar, porém, um dado surpreendente nesse Liraa que é o aumento de depósito de armazenamento de água na zona sul de Manaus. Os maiores índices foram encontrados no estrato 22 do bairro do Novo Israel (zona norte) com 5,5\%, no estrato 54 dos bairros do Morro da Liberdade, do São Lázaro e da Betânia (zona sul) com 5,6\%, no estrato 50 dos bairros do Aleixo e de Adrianópolis (zona centro-sul) com 6,4\% e no estrato 11 do bairro do Jorge Teixeira (zona leste) com $7,7 \%$. Vale ressaltar que a zona centro-oeste e alguns bairros da zona oeste apresentaram baixo risco da doença para esse período.

Manaus tem a maior parte de seu lixo coletado direta ou indiretamente, mas um volume significativo é queimado $(9,68 \%)$ ou lançado em terrenos baldios $(5,60 \%)$ e corpos d'água (6,04\%), constituindo um dos principais problemas ambientais da cidade (GEO MANAUS, 2002: 63). A coleta direta é realizada pela prefeitura de Manaus, porém não é regular, principalmente em muitos bairros das zonas norte e leste, onde o caminhão coletor não tem dia programado. Ainda é comum nesses bairros a prática de queimar o lixo nos quintais de casa, bem como descartar em terrenos baldios.

Como podemos observar, o Liraa torna-se um instrumento importante no conhecimento da distribuição espacial da dengue:

A análise geográfica pode contribuir significativamente para o desvendamento de causas e consequências e, portanto, para o avanço do conhecimento na área de saúde pública. A definição da escala adequada de estudo e de mapeamento dos diferentes fenômenos, entretanto, é de importância crucial para detectar as variações espaciais mais significativas e as relações entre elas e as variáveis ecológicas, demográficas, sociais, culturais e econômicas (...) (RIBEIRO, 2005: 66).

O controle da dengue torna-se um grande desafio, não só para os geógrafos, mas também para as políticas de controle de endemias. Segundo Barcellos (2008: 52), é preciso incorporar as características do lugar nas atividades de reconhecimento do território exigidas na atenção primária de saúde e nas ações de controle de endemias: 
A abordagem populacional dos problemas de saúde é uma consequência do conceito ampliado de saúde. A situação de saúde de uma população inclui os problemas e as necessidades desta população, e as respostas sociais organizadas. O perfil epidemiológico de uma população é o resultado da interação entre os dois processos. Para se fazer a vigilância da saúde é preciso entender como funcionam e se articulam num território as condições econômicas, sociais e culturais, como se dá a vida das populações, quais os atores sociais e a sua íntima relação com seus espaços, seus lugares (BARCELLOS et. al., 2006: 33).

Com base nisso, é de competência do Geógrafo da Saúde analisar o espaço como objeto para planejamento e organização das ações de saúde. Essas atividades devem ser capazes de contribuir para a constituição do espaço promotor de saúde. O Liraa acaba se tornando uma estratégia útil para o mapeamento de incidência da dengue, onde é possível planejar e/ou induzir políticas públicas de saúde que tenham capacidade de constituir esse espaço.

\section{Considerações finais}

A capital amazonense é um exemplo para confirmar que em áreas que mantêm temperaturas mais elevadas são mais suscetíveis à presença e à proliferação do mosquito Aedes aegypti. Dessa forma, a dengue é considerada uma doença tropical, pois a proliferação do mosquito ocorre em maior incidência em países tropicais, em razão do clima quente e úmido.

A capacidade que o mosquito transmissor da dengue tem de reproduzir em qualquer recipiente com água torna-se difícil manter o seu controle. É importante a participação do governo e da população em medidas que poderão ser úteis para o controle da dengue em Manaus.

Concluímos por meio de uma análise introdutória do Liraa que existem quatro zonas geográficas em Manaus que apresentam situações opostas no que se refere à incidência de dengue nessa análise da distribuição espacial: as zonas norte e leste que apresentaram alto risco e as zonas centro-oeste e oeste que apresentaram de médio a baixo risco da doença. 
As grandes áreas verdes desmatadas no perímetro urbano de Manaus aconteceram, nos últimos anos, principalmente na zona norte e na leste, onde ficou notório o descaso do poder público, refletindo até hoje em áreas com precárias condições de infraestrutura. Certamente, a maior influência na proliferação da dengue é a condição socioambiental criada pelo homem.

O grande problema socioambiental visto neste trabalho é o armazenamento de água em recipientes, que acabam tornando-se criadouros do mosquito Aedes aegypti, principalmente nos locais com precária infraestrutura urbana, como é o caso das zonas norte e leste de Manaus.

A coleta do lixo deve ser eficiente para evitar o surgimento de criadouros da dengue, geralmente em terrenos baldios. O serviço de água deve ser também eficiente, pois evitará que as pessoas armazenem água, pois, como foi observado, a falta de água obriga as pessoas a armazenar água em recipientes que poderão se tornar ambientes potenciais à proliferação do mosquito Aedes aegypti.

Consideramos que, pelos dados do Liraa, é possível analisar a incidência de dengue por meio de uma distribuição espacial, gerando mapas que servirão como ferramentas úteis para planejar políticas públicas de saúde. Daí a importância da Geografia da Saúde em produzir mapas que possam representar o espaço promotor da saúde.

\section{Referências}

AYOADE, J. O. O clima e o Homem. In: . Introdução à Climatologia para os Trópicos. 8. ${ }^{\mathrm{a}}$ ed. Rio de Janeiro: Bertrand Brasil, 2002.

BARCELLOS, Christovam. Problemas Emergentes da Saúde Coletiva e a Revalorização do Espaço Geográfico. In: BARCELLOS, Christovam (Org.). Território, ambiente e saúde. Rio de Janeiro: Editora Fiocruz, 2008. . (et. al.). Espaço geográfico e epidemiologia. In: BARCELLOS, Christovam \& SANTOS, Simone M. (Orgs.). Abordagens espaciais na saúde pública. Brasília: Ministério da Saúde / Fundação Oswaldo Cruz, 2006.

BRASIL. Ministério da Saúde. Diagnóstico rápido nos municípios para vigilância entomológica do Aedes aegypti no Brasil - Liraa: metodologia para avaliação dos índices de Breteau e Predial. Brasília: Ministério da Saúde, 2005 (Normas e 
Manuais Técnicos).

DONALÍSIO, Maria Rita. O dengue no espaço habitado. São Paulo: Hucitec / Funcraf, 1999 (Saúde em Debate/Série Samuel Pessoa).

GEO MANAUS. Projeto geo cidades: relatório ambiental urbano integrado. Rio de Janeiro: Consórcio Parceria 21, 2002.

IBGE. Censo Demográfico de 2000. Rio de Janeiro: IBGE, 2002. . Pesquisa Nacional de Saneamento Básico: 2000. Rio de Janeiro: IBGE, 2002.

INMET. Instituto Nacional de Meteorologia. Precipitação em Manaus durante o ano de 2008. Manaus: Inmet, 2009.

MENDONÇA, Francisco de A. Geografia e meio ambiente. 8. ${ }^{a}$ ed. São Paulo: Contexto, 2005 (Caminhos da Geografia).

RIBEIRO, Helena. Geografia da Saúde e da doença aplicada à poluição do ar em São Paulo. In: RIBEIRO, Helena (Org.). Olhares geográficos: meio ambiente e saúde. São Paulo: Editora Senac São Paulo, 2005.

ROJAS, L. B. I. \& TOLEDO, L. M. (Orgs.). Espaço e doença: um caminho sobre o Amazonas. Rio de Janeiro: Editora Fiocruz, 1998.

SIPAM. Sistema de Proteção da Amazônia. Estudo do desmatamento na zona urbana de Manaus e sua relação com a expansão demográfica. Manaus: Sipam / Censipam, 2007.

SOUZA, Renato Ferreira de. Associação entre fatores socioambientais e a presença do vetor da dengue: uma perspectiva da Geografia da Saúde na cidade de Manaus, 2010. Dissertação (Mestrado em Geografia). Instituto de Ciências Humanas e Letras, Universidade Federal do Amazonas, Manaus. 